\title{
Engaging employees through spiritual leadership
}

\author{
William D. Hunsaker ${ }^{a^{*}}$ and Woojin Jeong
}

${ }^{a}$ Associate Professor, School of Business Administration, Kyungpook National University, 80 Daehak-Ro, Buk-Gu, Daegu, 41566, South Korea ${ }^{b}$ School of Business Administration, Kyungpook National University, South Korea

\section{H R O N I C L E}

Article history:

Received: May 30, 2020

Received in revised format:

May 302020

Accepted: June 26, 2020

Available online:

June 26, 2020

Keywords:

Spiritual leadership

Work engagement

Organizational commitment

Employee well-being

Smart PLS

Workplace spirituality

\section{Introduction}

This paper explores the integration of Fry's (2003) spiritual leadership model and employee engagement in motivating employees' organizational commitment. Researchers and practitioners alike are currently interested in these constructs, at a time when younger employees increasingly exhibit disengagement with their work and a lack of organizational commitment, and as organizations struggle to meet the competitive pressures that can arise from a lack of fully engaged employees (Saks \& Gruman, 2014). Higher-order leadership constructs (Fry \& Kriger, 2009), including authentic leadership (Liu et al., 2018) and empowering leadership (Park et al., 2017), which capture the higher-order needs of employees in the workplace-for example, the innate desire to flourish at the workplace though meaningful work and healthy social connections with others (Fry, 2003; Saks, 2011) — have been shown to mitigate such challenges and engage workers. Likewise, this paper posits, that as a higherorder construct, spiritual leadership and its intrinsic motivational influence on employees' spiritual well-being (SWB) help employees to positively engage in their work (Fry, 2003; Hunsaker, 2018; Meyer \& Gagne, 2008).

Contemporary organizations require proactive, dedicated, and energetic employees — in other words, organizations need employees who are engaged with their work (Bakker, Albrecht, \& Leiter, 2011). A concept introduced by Kahn (1990), employee engagement is a motivational construct that harnesses not only the physical selves of employees to their work roles, but also their emotional and cognitive selves. Building on this definition, the meaning of engagement has evolved to encompass an employees' state of mind at the workplace, as regards their energy, enthusiasm, and concentration in their work (Schaufeli et

* Corresponding author

E-mail address: hunsaker@knu.ac.kr (W. D. Hunsaker)

(C) 2020 by the authors; licensee Growing Science, Canada doi: $10.5267 /$ j.msl.2020.6.042 
al., 2002). Both organizations and individuals benefit from this state of mind. Notably, more engaged employees enhance organizational competitiveness through their heightened sense of job satisfaction, organizational commitment, organizational citizenship behavior (OCB), innovative behavior, and lower turnover intentions, as well as improved customer satisfaction and productivity (Bailey et al., 2017; Bakker \& Albrecht, 2018; Rich, Lepine, \& Crawford, 2010). Job resources and personal resources have consistently been shown to facilitate an employee's work engagement, and are characterized as the physical, organizational, and socio-psychological aspects of the job and workplace that help employees to achieve their goals and a sense of well-being (Bakker et al., 2011; Saks, 2006). Additionally, leadership behavior has been demonstrated to impact the engagement of workers by means of its influence on organizational culture and climate (Albrecht, 2012; Saks \& Gruman, 2014; Ahmed et al., 2019).

Leadership shapes employee behavior by influencing their attitudes, such as their satisfaction, commitment, and well-being at the workplace, but also by means of performance-linked, motivational constructs such as work engagement (Bailey et al., 2017; Bakker et al., 2011; Dinh et al., 2014). Leadership influences employee engagement directly through supervisor support and indirectly through its effects on organizational culture and climate, as evidenced through constructs such as leader-member exchange and transformational leadership (Albrecht, 2012; Bailey et al., 2017; Saks \& Gruman, 2014). However, in addressing the well-being needs demanded by younger workers in contemporary organizations, leadership constructs are evolving into higher-order, multi-dimensional, value-based constructs that move beyond simply leadership behaviors and traits to encompass organizational culture and climate, and are characterized by a collective social influence that engages everyone and captures the deeper dimensions of the human experience at the workplace (Fry \& Kriger, 2008). As just such a higherorder construct, spiritual leadership is deeply connected to employees' SWB with promising research findings demonstrating that Fry's (2003) model of spiritual leadership significantly influences employee attitudes and performance (Chen et al., 2019; Fry, Vitucci, \& Cedillo, 2005; Hunsaker, 2019). As evidenced by research demonstrating the effects of workplace spirituality on work engagement (Milliman, Gatling, \& Kim, 2018; Saks, 2011; Hunsaker, 2018), this paper posits that the holistic effects of spiritual leadership and SWB positively influence not only employees' organizational commitment, but also their work engagement.

Covariance-based structural equation modeling (CB-SEM), which is a common analytical methodology used to test leadership models in business research, focuses on confirming theoretically established relationships (Hair et al., 2014). In contrast, an emerging methodology for testing such models is structural equation modeling (SEM) based on partial least squares (PLSSEM), which is geared toward exploring predicted relationships and the explained variances of endogenous variables (Hair et al., 2017). While organizational commitment and employee engagement have seen extensive empirical research within the leadership field, the predictive influence of spiritual leadership on work engagement has undergone little empirical research. Therefore, this paper applies a PLS-SEM approach to both confirm and explore the predictive relationships that exist between spiritual leadership, organizational commitment, and work engagement.

To summarize, the research objective of this paper is to examine the effects of spiritual leadership on organizational commitment through the intervening effects of work engagement, based on PLS-SEM. This paper should help us better understand the effects of higher-order leadership frameworks, such as spiritual leadership, on constructs such as work engagement and organizational commitment, but also afford us a better understanding of the viability of using emerging analytical methodologies, such as PLS-SEM, to examine these relationships.

\section{Theoretical Framework and Hypotheses}

The theoretical framework for this study integrates concepts from Fry's (2003) spiritual leadership theory, Schaufeli et al.'s (2002) theory of work engagement, Fredrickson's (2001) broaden-and-build theory of positive emotions, Demerouti et al.'s (2001) job demands-resources model (JD-R model), Wilensky's (1960) spillover theory, and Bakker and Demerouti's (2008) model of work engagement. This study argues that empowering organizational structures, which are characterized by organizational cultures that engage the "whole self" employees bring to the workplace, also help employees to broaden and build positive emotional resources, and are critical for employees to become more effective and engaged in their work (Fredrickson, 2001; Kanter, 1993). In addition, this study also hypothesizes that spiritual leadership, which is embedded in and embraces workplace spirituality concepts of meaningful work, community, and aligned values, is a critical mechanism for facilitating and ensuring employees access to these structures (Fry \& Nisiewicz, 2013; Milliman, Czaplewski, \& Fergusen, 2003). Moreover, this study reasons that job resources, such as emotional and social support from leaders and coworkers, in combination with empowering organizational structures, help employees to engage in their work by spilling over and satisfying their SWB needs for meaning and membership in the workplace while also simultaneously nurturing their interest in and commitment to their work (Demerouti et al., 2001; Fry et al., 2005; Schaufeli \& Bakker, 2004; Wilensky, 1960). Thus, as conceptualized by Bakker and Demerouti (2008), this paper contends that the job resources captured through spiritual leadership and SWB positively reinforce employees' work engagement, which, in turn, stimulates the development of organizational commitment by employees. 


\subsection{Spiritual leadership model}

Spiritual leadership is "a causal leadership theory for organizational transformation to create an intrinsically motivated, learning organization ... [with a purpose] to tap into the fundamental needs of both leader and follower for spiritual survival" (Fry et al., 2005, p. 836). Spiritual leadership is closely tied to workplace spirituality that provides the cultural context for employees to experience meaningful work, mutually aligned values, and a sense of community with coworkers in satisfying their spiritual survival needs (Fry, 2003; Milliman et al., 2003). Spiritual leadership is a collective social influence process that engages everyone; therefore, it represents both a cause and an effect as leaders and followers interact and share in the leadership experience (Cropanzano \& Mitchell, 2005; Fry \& Nisiewicz, 2013). Conceptually, spiritual leadership is considered a higher-order epistemological construct of leadership that addresses not only leadership behaviors, interactions, and traits but goes beyond these definitions to address the visions and values that comprise a "being-centered" approach to leadership (Fry \& Kriger, 2008). In this respect, spiritual leadership captures the deeper dimensions of the human experience that today's employees expect in the workplace through leadership based on qualities of the human spirit like love, service, compassion, harmony, and tolerance, rather than more traditional approaches to leadership such as transformational leadership that rely on vision, values, and various leader traits or behavioral contingencies (Fry, 2003; Fry \& Kriger, 2008).

As modeled by Fry (2003), spiritual leadership is a process with the primary objective of satisfying employees' SWB, or their sense of calling and membership in and at the workplace, which is underpinned by mutually shared and intrinsically motivating values within the organizational culture that are modeled as vision, hope/faith, and altruistic love. From a strategic perspective, the spiritual leadership model assumes that leaders establish a compelling vision that motivates employees' meaning and purpose in the workplace; but more importantly, the model assumes that leaders build and sustain a culture of mutually shared values that enable employees to feel understood and appreciated, which also cultivates the collective social influence between leaders and followers that engages everyone. While not explicitly stated, Fry's (2003) model assumes that altruistic values sustained within the organizational culture broaden employees' socio-psychological resources that can carry over and enrich employees' SWB and attitudes within the workplace (Fredrickson, 2001; Wilensky, 1960). In this respect, spiritual leadership influences individual differences as reflected through one's SWB. Therefore, by means of this process, spiritual leadership, through the mediating effects of SWB, has been demonstrated to positively affect organizational performance and individual workplace attitudes, such as organizational commitment, OCB, and life satisfaction, while also mitigating the undesirable influence of counterproductive work behavior, job burnout, and work-family conflict (Chen \& Yang, 2012; Fry et al., 2005; Hunsaker, 2020; Hunsaker \& Nam, 2017; Yang \& Fry, 2018).

\subsection{Work engagement and organizational commitment}

Work engagement is defined as "a positive, fulfilling, work-related state of mind that is characterized by vigor, dedication, and absorption" (Schaufeli et al., 2002, p. 74). Work engagement represents the way employees experience their work (Bakker et al., 2011; Schaufeli \& Bakker, 2003), as evidenced by their investment of personal, unique resources in their work and their inner connection with work tasks (Christian et al., 2011). Engaged individuals are energetic and mentally resilient, as represented by their state of vigor. Engaged employees are also strongly involved in and enthusiastic about their work, as represented by their state of dedication. Moreover, engaged workers are concentrated and immersed in their work, as represented by their state of absorption. While work engagement includes aspects of job satisfaction, job involvement, organizational commitment, and OCB, it is an independent and distinct concept (Christian et al., 2011; Macey \& Schneider, 2008; Saks, 2006). For example, unlike the attitude of organizational commitment that focuses on how employees identify with and attach to their organizations (Meyer \& Allen, 1991), work engagement is viewed as "the degree to which an individual is attentive and absorbed in the performance of their roles" (Saks, 2006, p. 602), instead of an attitude, and it also focuses on the performance of one's role rather than his or her extra-role behaviors. In summary, engagement is a standalone, motivational construct with overlapping aspects such as job satisfaction and organizational commitment that are better conceptualized as consequences rather than alternative conceptualizations of engagement (Bakker et al., 2011; Arokiasamy \& Tat, 2020).

Researchers have identified that the work engagement of employees is highly influenced by a mixture of personal and job resources, moderated by employees' responses to various job demands (Bakker \& Demerouti, 2008; Saks, 2006). Personal resources refer to an individual's psychological state, such as one's self-esteem, self-efficacy, resiliency, regulation of emotions, or psychological availability (Albrecht, 2010; Rich et al., 2010). Personal resources, which are reflected through one's cognitive and emotional self-expressions at work (May et al., 2004), also refer to the human spirit at work. Within the JD-R model framework (Bakker \& Demerouti, 2008; Demerouti et al., 2001), job resources refer to the motivational aspects of a job and the work environment that help employees to achieve their goals, stimulate personal development, and manage job demands. These resources include not only physical resources, but also social, emotional, and organizational facets of work, such as the social and emotional support of managers and coworkers, performance feedback, coaching, flexible work schedules, participation in decision making, and work climate (Albrecht, 2010; Bakker et al., 2011; Saks, 2011). Moreover, the effects of leadership can indirectly influence employees' work engagement by influencing their job and personal resources and helping them to derive meaningfulness and group identity from their work (Bakker \& Albrecht, 2018; Bakker et al., 2011; Christian et al., 2011; Liu et al., 2018; Park et al., 2017). For example, Saks (2011) expanded the scope of work engagement 
by modeling the influence of a spiritual work climate on work engagement, as explained through the dimensions of meaningfulness in and at work. Noting the effects of leadership on work engagement, researchers have revealed that leadership constructs, such as transformational and authentic leadership, played a positive role in fostering work engagement by stimulating meaning in one's work and positively influencing the underlying work culture (Carasco-Saul, Kim, \& Kim, 2014). Researchers have recently determined that distal organizational resources, such as the effects of leadership on organizational climate, influence employees’ proximal job resources and engagement (Albrecht, Breidahl, \& Marty, 2018).

Work engagement is also strongly associated with employee performance and work-related attitudes, such OCB, innovative behavior, job and life satisfaction, employee well-being, and organizational commitment (see Bailey et al., 2017; Bakker \& Albrecht, 2018; Kim et al., 2017). Researchers have determined that work engagement is a construct distinct from organizational commitment and both influences and is influenced by organizational commitment (see Kim et al., 2017). Beyond the direct effects of work engagement on organizational commitment, work engagement positively mediates the relationship between job resources, such as supervisor support and leadership, and organizational commitment (Albrecht, 2012; Kim et al., 2017; Saks, 2006). For instance, Saks (2006) explored employee engagement's role as an intervening mechanism between various antecedents, such as perceived supervisor and organizational support, and engagement consequences, such as organizational commitment and job satisfaction. Research findings have confirmed that work engagement plays a key mediating role in explaining the effects of supervisor support and other antecedent variables on the perceived organizational commitment of employees. Meanwhile, Albrecht (2012) explored the effects of organizational culture (i.e., employees' perception of fairness, openness, and support in the workplace) on employee engagement and organizational commitment through job resources, such as supervisory coaching. Research results have determined that organizational culture influences employees' organizational commitment through not only its direct effects on work engagement but also, more importantly, through its indirect effects by way of job resources.

\subsection{Hypothesized model}

This paper integrates the previously described concepts from established theories and empirical research into a proposed model that seeks to describe the influence of spiritual leadership and employees' perceived work engagement and organizational commitment (see Figure 1). First, this paper hypothesizes that employees' perceptions of the spiritual leadership environment enacted by their leaders should positively influence employees' work engagement to the extent that spiritual leadership resonates with employees' sense of SWB. Likewise, these perceptions of spiritual leadership should also positively influence employees' organizational commitment by instilling a heightened sense of SWB. Together, this paper hypothesizes that the perceived effects of spiritual leadership on employees' organizational commitment is best explained through the serial mechanisms of fostering a sense of SWB in employees, which, in turn, arouses their engagement in their work. In sum, the reasoning underlying this paper is that the manifest attributes of spiritual leadership within an organizational culture broaden and build employees' socio-psychological resources (Demerouti et al., 2001; Fredrickson, 2001), which spill over and fuel employees' SWB (Wilensky, 1960), which, in turn are demonstrated through energized states of work engagement and organizational commitment.

$\mathbf{H}_{1}$ : The work engagement of employees is positively influenced by spiritual leadership, as mediated through the effects of SWB.

$\mathbf{H}_{2}$ : The organizational commitment of employees is positively influenced by spiritual leadership, as sequentially mediated by the effects of SWB and work engagement.

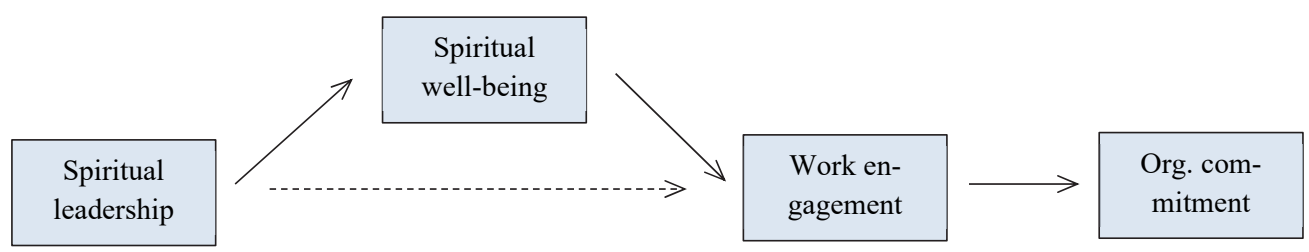

Fig. 1. Proposed model of spiritual leadership

\section{Methods}

\subsection{Sample and data collection}

This study focused on a general sample of millennial employees working within China's service, manufacturing, and public service sectors. Data were gathered through a survey that queried respondents regarding their assessments of spiritual leadership, work engagement, and organizational commitment. Surveys were distributed to 300 participants, of which 207 were deemed usable, consisting of $41.1 \%$ male and $58.9 \%$ female respondents. While all participants were under the age of 40 , most participants were under the age of $30(83.6 \%)$ and unmarried (59.9\%). In terms of education, most respondents held 
university degrees (78.3\%) and, as relates to employment, $71.5 \%$ of respondents had less than five years of work experience. Most respondents were employed in the service sector $(54.1 \%)$, in addition to the manufacturing sector (18.4\%), the public sector (16.4\%), and other industries (11.1\%).

\subsection{Instrumentation}

Measurement instruments were rated on five-point Likert scales, ranging from strongly disagree to strongly agree. The Cronbach's alpha reliabilities of the instruments are listed in Table 1. Spiritual leadership and SWB variables were assessed according to Fry et al.'s (2005) survey of spiritual leadership, which is comprised of five dimensions and 21 items that measured participants' self-rated perceptions of altruistic love, hope/faith, vision, meaning/calling, and membership. The latent variable of spiritual leadership was derived by means of SEM that modeled the three reflective dimensions of vision, hope, and altruistic love. Likewise, SWB was derived from the reflective dimensions of meaning and membership. The composite reliabilities of these latent dimensions were .96 and .93, respectively. Secondly, instrumentation for organizational commitment was based on Meyer and Allen's (1991) measure of affective organizational commitment, which is comprised of four items. Finally, instrumentation for work engagement was based on the Utrecht Work Engagement Scale (Schaufeli \& Bakker, 2003), which is comprised of three dimensions and 15 items that measured participants' self-rated perceptions of vigor, dedication, and absorption in their work. By means of modeling these three dimensions, the latent variable of work engagement was derived, demonstrating a composite reliability of .95 .

\subsection{Analysis methodology}

PLS-SEM was used to test the proposed relationships proposed in this paper, as opposed to CB-SEM, which has been the general methodology most commonly used in testing models in business research, including previous studies on spiritual leadership. Whereas CB-SEM focuses on confirming theorized relationships with a proposed model, the focus of PLS-SEM is exploring proposed relationships and maximizing their explained variance (Hair et al., 2014a). As an emerging SEM technique, PLS-SEM offers not only the advantage of concentrating on exploring and predicting relationships, but also of modeling data that is not normally distributed or based on relatively smaller sample sizes (Lowry \& Gaskin, 2014). Within the scope of this paper, while spiritual leadership, employee engagement, and organizational commitment are all well-established and empirically tested theories, spiritual leadership as a predictor of work engagement, combined with the proposed mediating effects of work engagement on organizational commitment has undergone little empirical research. Therefore, a PLS-SEM approach was employed to both confirm and explore the interrelationships between spiritual leadership, work engagement, and organizational commitment.

\section{Analyses and Results}

\subsection{Measurement model}

As represented in Table 1, the scale reliabilities of the four latent measures were significant, ranging between .74 and .95 , as well as positively correlated with each other, which supports this study's hypothesized relationships. While not shown, the inter-correlations between lower dimensions, including vision, hope, altruistic love, meaning, membership, vigor, dedication, absorption, and organizational commitment, were also significant $(\mathrm{p}<.01)$ and consistent with expected relationships.

Table 1

Descriptive statistics, reliabilities, and correlations $(N=207)$

\begin{tabular}{llllllllll}
\hline \multicolumn{1}{c}{ Variable } & M & SD & CR & AVE & 1 & 2 & 3 & 4 \\
\hline 1 & SL & 3.52 & .73 & .96 & .62 & .95 & & & \\
2 & SWB & 3.51 & .73 & .93 & .67 & .87 & .92 & & \\
3 & WE & 3.58 & .66 & .95 & .61 & .71 & .78 & .95 & .69 \\
4 & OC & 3.26 & .70 & .85 & .66 & .63 & .65 & .74 \\
\hline
\end{tabular}

Note. The correlation coefficients were all significant at $\mathrm{p}<.01$. Cronbach's alpha reliabilities are represented in boldface.

The reliability and validity of the measurement model was assessed using composite reliabilities (CR) and average variance extracted (AVE; Fornell \& Larcker, 1981). As shown in Table 1, the calculated CR and AVE values were all above .70 and .50, respectively, which met the recommended thresholds in support of the model's validity (Hair et al., 2014). The overall model fit was assessed by way of the standardized root mean square residual (SRMR). The derived SRMR coefficient was .06, which was lower than the suggested threshold coefficient of .08, suggesting an overall good fit of this paper's proposed model (Hair et al., 2017).

\subsection{Hypotheses analysis}

PLS-SEM based on principal components estimation through SmartPLS was used to assess the structural model by examining the path relationships in the model. First, the predictors in the structural model were examined for collinearity through variance 
inflation factor (VIF) values, which were within the suggested threshold range of between .20 to 5.0 (Hair et al., 2017). Second, as depicted in Figure 2, path analysis determined that the proposed relationships from spiritual leadership to SWB, work engagement, and organizational commitment were both positive and significant $(p<.01)$. Notably, the effects from spiritual leadership to SWB and from SWB to work engagement were relatively high (i.e., above .75), supporting the importance of spiritual leadership and SWB in predicting employee work engagement. In contrast, the relatively lower path coefficient from work engagement to organizational commitment suggests that while work engagement impacts employees' organizational commitment, there are other predictors of organizational commitment that are not captured through this proposed model. Next, as illustrated in Fig. 2, the explained levels of variance (i.e., $R^{2}$ ) of the endogenous variables SWB, work engagement, and organizational commitment were $.77, .62$, and .49 , respectively. Based on PLS-SE rules-of-thumb (i.e., high $=.75$, moderate $=.50$, low $=.25)$ regarding the total predictive strength of exogenous variables on endogenous variables in a model, these levels of explained variance demonstrate substantial effects of spiritual leadership on SWB, while the effects on work engagement and organizational commitment should be considered moderate (Hair et al., 2014a). In addition to $R^{2}$ values, the effect sizes of the exogenous variables on endogenous variables through the $f^{2}$ effect were calculated. Based on guidelines (Hair et al., 2017) for assessing $f^{2}$ effects (i.e., small $=.02$, medium $=.15$, large $=.35$ ), the $f^{2}$ effects of spiritual leadership on organizational commitment were medium $(.12, p<.10)$, while the effects of work engagement on organizational commitment were slightly better $(.15, p<.05)$ and the effects of SWB on work engagement were relatively high $(.24, p<.01)$.

Hypotheses were tested using path analysis and mediation testing guidelines, which examined the significance of both direct and indirect hypothesized path relationships as previously proposed in this paper (Preacher \& Hayes, 2004). The hypotheses in this study proposed that employees' work engagement and organizational commitment would be positively influenced by spiritual leadership through the intervening effects of SWB and work engagement, respectively. First, excluding all mediating effects, the direct effects of spiritual leadership on work engagement $(\beta=.73 ; p<.01)$ and organizational commitment $(\beta$ $=.64 ; \mathrm{p}<.01)$ were both positive and significant. Next, mediating variables were added to the structural model to assess the indirect effects of spiritual leadership on endogenous variables (see Table 2). The results confirmed that the indirect effects of spiritual leadership on work engagement through SWB were $.56(\mathrm{p}<.01)$, lending support to Hypothesis 1 . Moreover, the indirect serial mediating effects of SWB and work engagement on organizational commitment were $.22(\mathrm{p}<.01)$, while the specific indirect effects of each mediator on organizational commitment were not significant, lending support to Hypothesis 2. In addition, excluding the effects of spiritual leadership in the model, the embedded relationship of SWB's influence on organizational commitment through work engagement indicated that employees' organizational commitment was mediated through the effects of work engagement $(\beta=.33, p<.01)$. In sum, the direct effects of spiritual leadership on endogenous variables, inclusive of mediating variables, fell to .17 $(p=$ n.s.) for work engagement and $.34(p<.01)$ for organizational commitment, showing the relative importance of the mediators in explaining the relationship of spiritual leadership on work engagement and organizational commitment.

Table 2

Mediation results of proposed model

\begin{tabular}{|c|c|c|c|c|c|}
\hline \multirow[b]{2}{*}{ Path } & \multirow{2}{*}{$\begin{array}{l}\text { Direct effects } \\
\text { (a) }\end{array}$} & \multicolumn{2}{|c|}{ Indirect mediation effects } & \multirow{2}{*}{$\begin{array}{c}\text { Serial effects } \\
\text { (d) }\end{array}$} & \multirow{2}{*}{$\begin{array}{c}\text { Total effects } \\
(a+b+c+d)\end{array}$} \\
\hline & & $\mathrm{SWB} \rightarrow(\mathrm{b})$ & $\mathrm{WE} \rightarrow(\mathrm{c})$ & & \\
\hline $\mathrm{SL} \rightarrow \mathrm{SWB} \rightarrow \mathrm{WE} \rightarrow \mathrm{OC}$ & .34 & $.02 *$ & $.06^{*}$ & .22 & .64 \\
\hline $\mathrm{SL} \rightarrow \mathrm{SWB} \rightarrow \mathrm{WE}$ & $.17 *$ & .56 & & & .73 \\
\hline $\mathrm{SWB} \rightarrow \mathrm{WE} \rightarrow \mathrm{OC}$ & .29 & & .33 & & .62 \\
\hline
\end{tabular}

Note: *not significant. All path relationships are significant at $p<.01$, except as noted. Serial effects refer to the indirect, sequential effects of the mediating variables. Model 3 indicates the independent effects of SWB and WE on OC, excluding the effects of SL. SL $=$ spiritual leadership, $\mathrm{SWB}=$ spiritual well-being, $\mathrm{WE}=$ work engagement, $\mathrm{OC}=$ organizational commitment

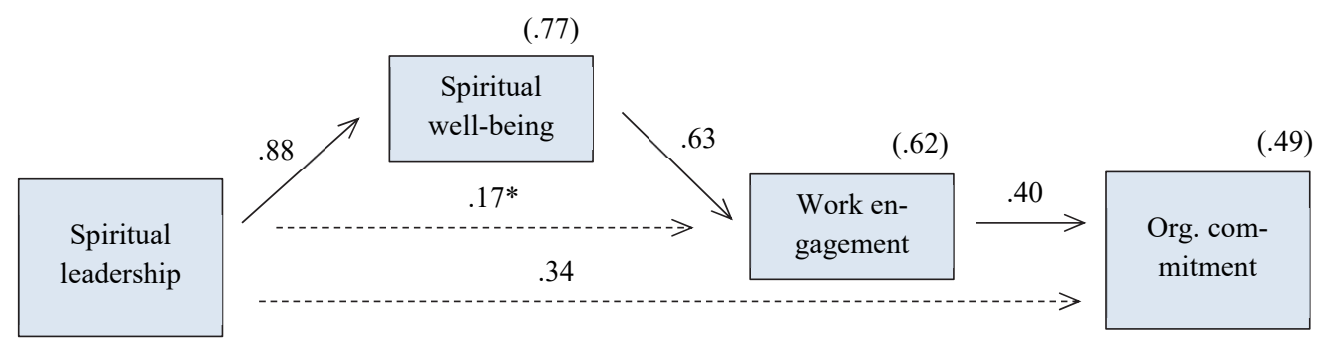

Fig. 2. Path coefficients and explained variance $\left(R^{2}\right)$ of the proposed structural model.

Note: * not significant. Except as noted, all path relationships were significant $(p<0.01)$. Explained variance $\left(R^{2}\right)$ proportions are shown in parentheses. 


\section{Discussion}

The purpose of this study was to investigate how spiritual leadership and SWB affect employees' work engagement and its subsequent influence on organizational commitment. Research results demonstrated that employees' work engagement is significantly impacted by spiritual leadership, influenced by a heightened sense of meaningfulness in and at the workplace (Pratt \& Ashforth, 2003), or SWB, which expands the constructs of spiritual leadership and employee engagement. Additionally, the results showed that employees' work engagement influence their commitment to the organization. In addition, as an intervening model, research results showed that organizational commitment is also explained through the sequential mediating effects of SWB and work engagement, which supports the call of researchers to more fully explore the intrinsic motivational mechanisms that explain the effects of spiritual leadership on employee behaviors (Chen et al., 2019; Meyer \& Gagne, 2008).

These findings suggest that young workers' engagement and commitment to their work and organizations are roused when the organization and its leaders satisfy the higher-order, human spirit needs, such as service, respect, tolerance, and compassion, that young workers expect in the workplace (Fry \& Kriger, 2008). This paper's findings suggest that the socio-psychological resources, such as SWB, that enable employees to become more fully engaged in their work can be enhanced through the influence of spiritual leadership (Fredrickson, 2001). In other words, the findings suggest that the mutually aligned values and collective social processes between leaders and employees that comprise spiritual leadership are the catalysts that spark feelings of well-being and intrinsic desire in employees to more fully engage in their work (Fry, 2003). These findings are aligned with existing research that shows the effects of spiritual leadership on employee attitudes and work roles, such as organizational commitment, OCB, and work-family conflict (Chen \& Yang, 2012; Fry et al., 2005; Hunsaker, 2020), and the positive relationship between higher-order leadership constructs and employee engagement (Liu et al., 2018; Park et al., 2017).

A secondary purpose of this study was to investigate the use of PLS-SEM as an effective, explanatory methodology of the predictive effects of spiritual leadership on endogenous variables. This was pursued through the analysis of the strength and significance of predicted relationships and the level of explained variance that spiritual leadership exhibits on endogenous variables (Hair et al., 2017). The research findings lend strong support to spiritual leadership as being a predictor of employees' work engagement and organizational commitment, as evidenced by not only the significance and strength of the path coefficients between these relationships (see Figure 2), but also through the moderate to high explained variance (i.e., $R^{2}$ ) of spiritual leadership on SWB, work engagement, and organizational commitment. Combined with the assessed $f^{2}$ effects of spiritual leadership on the endogenous variables in this study, these combined effects indicate that spiritual leadership plays an important predictive role in employees' work engagement and organizational commitment.

From a practical perspective, this study suggests that an organizational culture fueled by spiritual leadership not only meets the higher-order needs of young employees connected to being understood, appreciated, and making a meaningful impact at the workplace but also, more importantly, that such a climate provides employees with the personal resources to more fully and freely engage in their work. Based on this paper's findings, to engage employees, practitioners should actively build and sustain organizational climates that embrace the "whole" selves of young workers in satisfying the attributes of the human spirit, for example, service, honesty, respect, empathy, dignity, comradery, and perseverance, that are fundamental underlying values of workplace spirituality and spiritual leadership (Fry, 2003; Ferguson \& Milliman, 2008; Lee, Lovelace, \& Manz, 2014). Moreover, to influence the work engagement of employees, practitioners should confidently hire, promote, and train individuals that exhibit spiritual leadership behaviors, such as the ability to build a vision, strive for excellence, "walk the talk," and altruistically serve and empower others (Fry \& Nisiewicz, 2013). Research findings have demonstrated that transformational leaders can impact the engagement of workers (Breevaart \& Bakker, 2018) and that such interventions require not only senior leadership endorsement but also sustained, combined efforts at the organizational, job, and individual levels of the organization (Bakker et al., 2011). Finally, this study suggests that aside from the impact of spiritual leadership and work engagement on the commitment of employees to their organizations, other positive organizational outcomes, such as innovation and $\mathrm{OCB}$, can arise from the intervening interaction of spiritual leadership and employee engagement. Given the perceived importance of employee engagement on organizational performance, future research should investigate the intervening influence of spiritual leadership and work engagement, both as a mediator and moderator, on extra-role employee behaviors like innovative work behavior.

This study has several limitations. First, despite the predictive benefits of PLS-SEM, the data of this study relied on crosssectional, self-reported data, which might lead to common method bias issues and reduce the generalizability of causal effects. To reduce such bias, survey participants were assured of anonymity, data were gathered from multiple sources, and diverse validity testing was performed using SEM. Second, the generalization of this study's results may be limited in Western contexts due to the fact that the data were gathered from a Confucian culture. However, given the rise of individualism in Confucian cultures due to the influence of Westernization, collectivist tendencies are diminishing, which suggests greater generalizability of these results than previously assumed. Third, this study was based on a sample of employees from a variety of contemporary industries in order to improve the generalizability of results. However, given the unique leadership and cultural 
attributes that underpin the motivational process of spiritual leadership, future studies should validate these results in purposive, comparative samplings of known spiritual and contemporary organizations, as well as multi-group, multi-divisional analyses to test the effects of spiritual leadership across both spiritual and "normal" organizations, and employees from diverse divisions or departments. Future studies can address these limitations by means of longitudinal and cross-cultural research designs.

\section{References}

Ahmed, U., Majid, A., Al-Aali, L., \& Mozammel, S. (2019). Can meaningful work really moderate the relationship between supervisor support, coworker support and work Engagement?. Management Science Letters, 9(2), 229-242.

Albrecht, S. L. (Ed.). (2010). Handbook of employee engagement: Perspectives, issues, research and practice. Glos, England: Edward Elgar.

Albrecht, S. L. (2012). The influence of job, team and organizational level resources on employee well-being, engagement, commitment and extra-role performance. International Journal of Manpower, 33(7), 840-853.

Albrecht, S., Breidahl, E., \& Marty, A. (2018). Organizational resources, organizational engagement climate, and employee engagement. Career Development International, 23(1), 67-85.

Arokiasamy, A., \& Tat, H. (2020). Exploring the influence of transformational leadership on work engagement and workplace spirituality of academic employees in the private higher education institutions in Malaysia. Management Science Letters, 10(4), 855-864.

Bailey, C., Madden, A., Alfes, K., \& Fletcher, L. (2017). The meaning, antecedents and outcomes of employee engagement: A narrative synthesis. International Journal of Management Reviews, 19(1), 31-53.

Bakker, A. B., \& Albrecht, S. (2018). Work engagement: Current trends. Career Development International, $23(1), 4-11$.

Bakker, A. B., Albrecht, S. L., \& Leiter, M. P. (2011). Key questions regarding work engagement. European Journal of Work and Organizational Psychology, 20(1), 4-28.

Bakker, A. B., \& Demerouti, E. (2008). Towards a model of work engagement. Career Development International, 13(3), 209-223.

Breevaart, K., \& Bakker, A. B. (2018). Daily job demands and employee work engagement: The role of daily transformational leadership behavior. Journal of Occupational Health Psychology, 23(3), 338.

Carasco-Saul, M., Kim, W., \& Kim, T. (2015). Leadership and employee engagement: Proposing research agendas through a review of literature. Human Resource Development Review, 14(1), 38-63.

Chen, C., \& Yang, C. (2012). The impact of spiritual leadership on organizational citizenship behavior: A multi-sample analysis. Journal of Business Ethics, 105(1), 107-114.

Chen, S., Jiang, W., Zhang, G., \& Chu, F. (2019). Spiritual leadership on proactive workplace behavior: The role of organizational identification and psychological safety. Frontiers in Psychology, 10, 1206.

Christian, M. S., Garza, A. S., \& Slaughter, J. E. (2011). Work engagement: A quantitative review and test of its relations with task and contextual performance. Personnel Psychology, 64(1), 89-136.

Cropanzano, R., \& Mitchell, M. S. (2005). Social exchange theory: An interdisciplinary review. Journal of Management, 31(6), 874-900.

Demerouti, E., Bakker, A. B., Nachreiner, F., \& Schaufeli, W. B. (2001). The job demands-resources model of burnout. Journal of Applied Psychology, 86(3), 499-512.

Dinh, J. E., Lord, R. G., Gardner, W. L., Meuser, J. D., Liden, R. C., \& Hu, J. (2014). Leadership theory and research in the new millennium: Current theoretical trends and changing perspectives. The Leadership Quarterly, 25(1), 36-62.

Ferguson, J., \& Milliman, J. (2008). Creating effective core organizational values: A spiritual leadership approach. Intl Journal of Public Administration, 31(4), 439-459.

Fornell, C., \& Larcker, D. F. (1981). Evaluating structural equation models with unobservable variables and measurement error. Journal of Marketing Research, 18(1), 39-50.

Fredrickson, B. L. (2001). The role of positive emotions in positive psychology: The broaden-and-build theory of positive emotions. American Psychologist, 56(3), 218-226.

Fry, L. W. (2003). Toward a theory of spiritual leadership. The Leadership Quarterly, 14(6), 693-727.

Fry, L. W., \& Kriger, M. (2009). Towards a theory of being-centered leadership: Multiple levels of being as context for effective leadership. Human Relations, 62(11), 1667-1696.

Fry, L. W., \& Nisiewicz, M. (2013). Maximizing the triple bottom line through spiritual leadership. Stanford: Stanford Business Books.

Fry, L. W., Vitucci, S., \& Cedillo, M. (2005). Spiritual leadership and army transformation: Theory, measurement, and establishing a baseline. The Leadership Quarterly, 16(5), 835-862.

Hair, J. F., Black, W. C., Babin, B. J., \& Anderson, R. E. (2014). Multivariate data analysis (7th ed.). London: Pearson Education.

Hair, J. F., Hult, G. T. M., Ringle, C. M., \& Sarstedt, M. (2017). A primer on partial least squares structural equation modeling (PLS-SEM). Thousand Oaks: Sage.

Hair, J. F., Sarstedt, M., Hopkins, L., \& Kuppelwieser, V. G. (2014). Partial least squares structural equation modeling (PLSSEM). European Business Review, 26(2), 106-121. 
Hunsaker, W. D. (2018). Workplace spirituality and well-being: Examining the relationship on employee engagement in south korea. Journal for Global Business Advancement, 11(5), 650-664.

Hunsaker, W. D. (2019). Spiritual leadership and job burnout: Mediating effects of employee well-being and life satisfaction. Management Science Letters, 9(8), 1257-1268.

Hunsaker, W. D. (2020). Spiritual leadership and work-family conflict: Mediating effects of employee well-being. Personnel Review, doi:10.1108/PR-04-2019-0143

Hunsaker, W. D., \& Nam, J. G. (2017). Counterproductive work behavior: Mitigating role of spiritual leadership. Advanced Science Letters, 23(3), 1656-1659.

Kahn, W. A. (1990). Psychological conditions of personal engagement and disengagement at work. Academy of Management Journal, 33(4), 692-724.

Kanter, R. M. (1993). Men and women of the corporation. New York: Basic Books.

Kim, W., Kim, J., Woo, H., Park, J., Jo, J., Park, S., \& Lim, S. Y. (2017). The relationship between work engagement and organizational commitment: Proposing research agendas through a review of empirical literature. Human Resource Development Review, 16(4), 350-376.

Lee, S., Lovelace, K. J., \& Manz, C. C. (2014). Serving with spirit: An integrative model of workplace spirituality within service organizations. Journal of Management, Spirituality \& Religion, 11(1), 45-64.

Liu, Y., Fuller, B., Hester, K., Bennett, R. J., \& Dickerson, M. S. (2018). Linking authentic leadership to subordinate behaviors. Leadership \& Organization Development Journal, 39(2), 218-233.

Lowry, P. B., \& Gaskin, J. (2014). Partial least squares (PLS) structural equation modeling (SEM) for building and testing behavioral causal theory: When to choose it and how to use it. IEEE Transactions on Professional Communication, 57(2), 123-146.

Macey, W. H., \& Schneider, B. (2008). The meaning of employee engagement. Industrial and Organizational Psychology, 1(1), 3-30.

May, D. R., Gilson, R. L., \& Harter, L. M. (2004). The psychological conditions of meaningfulness, safety and availability and the engagement of the human spirit at work. Journal of Occupational and Organizational Psychology, 77(1), 11-37.

Meyer, J. P., \& Allen, N. J. (1991). A three-component conceptualization of organizational commitment. Human Resource Management Review, 1(1), 61-89.

Meyer, J. P., \& Gagne, M. (2008). Employee engagement from a self-determination theory perspective. Industrial and Organizational Psychology, 1(1), 60-62.

Milliman, J., Czaplewski, A. J., \& Ferguson, J. (2003). Workplace spirituality and employee work attitudes: An exploratory empirical assessment. Journal of Organizational Change Management, 16(4), 426-447.

Milliman, J., Gatling, A., \& Kim, J. S. (2018). The effect of workplace spirituality on hospitality employee engagement, intention to stay, and service delivery. Journal of Hospitality and Tourism Management, 35, 56-65.

Park, J. G., Kim, J. S., Yoon, S. W., \& Joo, B. (2017). The effects of empowering leadership on psychological well-being and job engagement. Leadership \& Organization Development Journal, 38(3), 350-367.

Pratt, M. G., \& Ashforth, B. E. (2003). Fostering meaningfulness in working and at work. In K. S. Cameron, J. E. Dutton \& R. E. Quinn (Eds.), Positive organizational scholarship: Foundations of a new discipline (pp. 309-327). San Francisco: Berrett-Koehler.

Preacher, K. J., \& Hayes, A. F. (2004). SPSS and SAS procedures for estimating indirect effects in simple mediation models. Behavior Research Methods, 36(4), 717-731.

Rich, B. L., Lepine, J. A., \& Crawford, E. R. (2010). Job engagement: Antecedents and effects on job performance. Academy of Management Journal, 53(3), 617-635.

Saks, A. M. (2006). Antecedents and consequences of employee engagement. Journal of Managerial Psychology, 21(7), 600619.

Saks, A. M. (2011). Workplace spirituality and employee engagement. Journal of Management, Spirituality \& Religion, 8(4), 317-340.

Saks, A. M., \& Gruman, J. A. (2014). What do we really know about employee engagement? Human Resource Development Quarterly, 25(2), 155-182.

Schaufeli, W. B., \& Bakker, A. B. (2003). Utrecht work engagement scale: Preliminary manual. Occupational Health Psychology Unit, Utrecht University, Utrecht,

Schaufeli, W. B., \& Bakker, A. B. (2004). Job demands, job resources, and their relationship with burnout and engagement: A multi-sample study. Journal of Organizational Behavior, 25(3), 293-315.

Schaufeli, W. B., Salanova, M., González-Romá, V., \& Bakker, A. B. (2002). The measurement of engagement and burnout: A two sample confirmatory factor analytic approach. Journal of Happiness Studies, 3(1), 71-92.

Wilensky, H. L. (1960). Work, careers and social integration. International Social Science Journal, 12, 543-560.

Yang, M., \& Fry, L. W. (2018). The role of spiritual leadership in reducing healthcare worker burnout. Journal of Management, Spirituality \& Religion, 15(4), 305-324. 
(C) 2020 by the authors; licensee Growing Science, Canada. This is an open access article distributed under the terms and conditions of the Creative Commons Attribution (CC-BY) license (http://creativecommons.org/licenses/by/4.0/). 